\title{
Evidence on the arbitrage efficiency of SPI index futures and options markets*
}

\author{
Steven $\mathrm{Li}^{* *}$ and Elia Alfay \\ School of Economics and Finance \\ Queensland University of Technology \\ Brisbane, Australia
}

\begin{abstract}
This paper investigates arbitrage opportunities from the Australian market using the futures and futures option contracts traded on the Sydney Futures Exchange (SFE) within a put-call-futures-parity (PCFP) framework. A thorough ex post analysis is first carried out. Tick-by-tick transaction price data allow the futures contracts, the call futures options and the put futures options to be matched within a one minute interval. This paper take into account the realistic transaction costs that an arbitrager has to incur, including the implicit bid-ask spread. The results reveal a significant number of violations with $25.40 \%$ of the sample breaching the PCFP equation with an average profit of 6.733 index points for SFE member firms. Ex ante tests are also conducted whereby the trios that signified an ex post profit for members were lagged up to 3 minutes before being executed. The results were similar to the ex post results casting doubt on the efficiency and integration between these two derivative markets in Australia.
\end{abstract}

Key words: Put-call-futures parity, market efficiency, SPI index, futures, options JEL Classification: G13, G14

\footnotetext{
${ }^{*}$ This paper has been presented in the Accounting and Finance Association of Australia and New Zealand (AFAANZ) 2005 conference. The authors are grateful to the conference participants for a few useful comments.

** Corresponding author, Email: s.li@qut.edu.au, Tel: 61-7-38642521
} 


\section{Introduction}

This paper investigates the arbitrage efficiency between two derivative markets in the Australian setting. The efficiency of the derivative markets is important not only to investors for speculation, hedging, and investment purposes, but also to regulators and society as a whole (Fung \& Fung, 1997). Therefore the predominant focus of this paper is to provide evidence on the size and frequency of arbitrage opportunities between the futures and options on the index futures contracts traded on the Sydney Futures Exchange (SFE).

Interestingly, the contracts employed are ideal in making inferences in relation to market efficiency, while the model utilised mitigates many problems such as the jointhypothesis problem. This is achieved by using a relative pricing model, one that is based on a no-arbitrage principle. The no-arbitrage principle that is used in Put-CallParity (PCP) is a powerful tool in the pricing of financial assets as it does not require strong assumptions about trader's beliefs nor about market price dynamics. This makes it possible to undertake a test of arbitrage profitability without making restrictive assumptions that may be unrealistic. All that is really required are a few rational agents who stand ready to eliminate any arbitrage opportunities as and when they arise.

The SFE futures and futures options are used to examine the arbitrage efficiency between these two derivative markets within a PCFP framework. The Share Price Index (SPI) futures options traded on the SFE are one of a few contracts traded around the world which have futures-style-margining whereby no premium is paid upfront but margins are posted to enter into the contracts. These contracts are coined 'pure' options (Duffie, 1989) and are different from the 'conventional' options traded around the world. A large body of literature has investigated the original PCFP model, however, the majority of studies utilise conventional options which require the premium to be paid upfront and in full. This paper joins the small body of literature in examining options which have futures-style-margining. We thus focus on arbitrage using the PCFP condition developed by Lieu (1990).

To test for arbitrage opportunities, the futures and futures option contracts need to be matched within a one-minute interval which mitigates the non-synchronous price 
problem. This is undertaken mainly because arbitrage is based on the premise of simultaneously buying low and selling high in order to make a riskless profit. Tickby-tick data permits the three contracts to be matched within a narrow time interval for examination. A total of 748 matched trios over the periods $2^{\text {nd }}$ January $2001-31^{\text {st }}$ March 2004 are used in the PCFP tests.

This research is motivated by the fact that PCFP should hold in well developed and integrated markets such as the Australian market which is relatively liquid. Prices in derivative markets should conform to parity relationships more strongly than in other types of markets because market makers set prices of these instruments taking into consideration various interrelationships (Lee and Nayar, 1993). Moreover, it appears that holders of futures contracts hedge their exposure with the companion options and vice-versa; hence, suggesting that the two contract prices should conform to the parity relationship (Draper and Fung, 2002). Deviations in the PCFP equation lead to arbitrage opportunities which in well developed and integrated markets should hardly occur and short lived. For this reason, it is important to examine the implications of the parity relationship and determine whether arbitrage opportunities are available and viable when all costs are considered including the implicit bid-ask spread.

Finally, in addition to making comments in relation to ex post results, ex ante tests are also undertaken. These tests allow for an execution lag of up to three minutes before establishing all legs in the futures and option markets. Additionally, the sample is stratified based on different factors such as calendar years, moneyness, maturity and whether a long or short arbitrage strategy is observed. This is undertaken to gain further insights into PCFP and arbitrage efficiency.

This paper is structured as follows. Section 2 provides a literature review. Section 3 illuminates on the methodology. Section 4 discusses the contracts and data utilised. Section 5 presents the empirical results. Section 6 provides a conclusion and fruitful areas for futures research.

\section{Literature review}

Stoll (1969) developed the PCP equation while Merton (1973) demonstrated that PCP can only be stated as inequalities for American options. A large number of derivative 
securities can be used to test for arbitrage opportunities within a PCP framework. These include index options and index futures, index futures and the options on the futures contracts which are examined in this paper, index futures and the underlying index and index futures and stock, only to name a few. This area in the literature is fairly well researched. Many studies have examined the put-call parity (PCP) relationship mainly in the US market both empirically and theoretically. Studies such as, Stoll (1969) and Gould and Galai (1974) test PCP using stock, Lee and Nayar (1993), Fung and Mok (2001) and Draper and Fung (2002) examine index futures and index options, Twite (1993) and Easton (1997) utilise index futures and options on the futures contracts with futures-style margining and MacKinlay and Ramaswamy (1988) and Chung (1991) investigate arbitrage between index futures and the underlying index.

Many different versions of PCFP have been proposed which take different securities into consideration. Tucker (1991) and Lee and Nayar (1993) demonstrated that PCFP holds for index futures and index options. This version of PCP is known as put-callfutures-parity (PCFP). The joint efficiency of the options and futures markets using PCFP has been researched by Fung and Fung (1997) and Fung and Mok (2001) who investigated the Hang Seng index in Hong Kong while Draper and Fung (2002) analysed the FTSE-100 index in London. These studies use PCFP and the options utilised are European in exercise style. Although they all find arbitrage opportunities, these opportunities are small and short lived. Hence, these studies support the efficient market paradigm as in Lee and Nayar (1993). ${ }^{1}$

Asay (1982) and Lieu (1990) developed the PCFP equation which will be utilised in investigating arbitrage opportunities in this paper. The options which are used, however, must be options on futures contracts that are marked-to-market instead of conventional options whereby the premium has to be paid upfront and in full. They also show that even if the options are American in exercise style, such as the SFE futures options, the parity equation still holds because it is never rational to exercise an American marked-to-market futures option early.

Research on the Australian market testing for violations in the PCP equation is limited only to a few studies in the literature. Although there has been an immense amount of

\footnotetext{
${ }^{1}$ All these studies analyse the put-call-futures-parity relationship adjusting for transaction costs.
} 
work examining this relation abroad, the Australian market has not attracted much attention. Loudon (1988), Grey (1989) and Taylor (1990) investigated PCP using American options whereby the proof of this theorem can be seen in Merton (1973) while Cox and Rubinstein (1985) incorporate dividends into the model.

Twite (1993) examined the relationship between the SPI All Ordinaries futures and the futures options between $17^{\text {th }}$ June 1985 and $30^{\text {th }}$ December 1992. Daily closing prices were used in the analysis consisting of bid-ask quotes. Transaction costs were explicitly accounted for which included exchange fees, negotiated brokerage and the SFE levy as well as the bid-ask spread. The results revealed that arbitrage opportunities were not viable after considering all costs including the bid-ask spread.

Easton (1997) provides a complete analysis of the major contracts traded on the SFE using intra-day data in the period from January 1993 to December 1994. He examined the All-Ordinaries SPI, 90-Day Bank Accepted Bills, the 3-year and 10-year Treasury bond contracts. Although Lieu (1990) stated that PCFP does not apply to interest rate options, Chen and Scott (1993) showed that the PCFP relation does hold on interest rate options even with stochastic interest rates. Easton (1997) concluded that the parity relation holds fairly well and explained that the exact parity relation is seen in between $15 \%$ to one third of all cases depending on the contract analysed. Although this study does examine PCFP it fails to conduct ex ante tests which are true tests of market efficiency. The last two studies discussed employed the PCFP condition developed by Lieu (1990) which is also used in this paper.

\section{Methodology}

In this section, we first recall the put-call-futures parity which is used in this paper. Then we discuss some technical issues related to the PCFP test and issues related to the ex ante tests.

\subsection{Put-call-futures-parity with futures-style margining}

This study will examine the efficiency of the options and futures markets in the Australian setting by using a parity relationship derived by Lieu (1990). This parity relationship is a mathematical identity that should hold in well developed and 
integrated markets without transaction costs. To empirically test this parity relationship, the index futures and futures option contracts traded on the SFE are utilised. The PCFP is given as:

$$
F_{t}-X-C_{t}+P_{t}=0
$$

where

$F_{t}=$ Actual futures price;

$X=$ Exercise price for put and call futures options;

$C_{t}=$ Call futures options price and

$P_{t}=$ Put futures option price.

Note that the above notation is used throughout this paper. For the formal proof of PCFP relationship we refer to Lieu (1990).

Rearranging Equation (1) gives the theoretical price of the futures contract as

$$
F_{t}=C_{t}+X-P_{t}
$$

If Equation (2) is violated then an arbitrage opportunity exists. There are two types of strategies that can be undertaken to eliminate an arbitrage opportunity, notably, a long arbitrage strategy when the actual futures price is relatively underpriced and a short arbitrage strategy when the actual futures price is relatively overpriced.

Note that we have ignored the transaction costs in the above discussion. An introduction of transactions costs (TC) alters the arbitrage relationship by creating a band around the theoretical futures price that would result in no arbitrage profits even if deviations in Equation (1) are detected. ${ }^{2}$ A long arbitrage strategy where the actual futures price is underpriced and incorporating transaction costs $(T C)$ is profitable when

$$
F_{t}<C_{t}+X-P_{t}-T C
$$

\footnotetext{
${ }^{2}$ Transaction costs are assumed to include the cost of trading in all three instruments, notably, the futures contract, put and call futures options. The costs will vary according to different market participants. Additionally, the bid-ask spread is estimated and included in the total transaction costs figure.
} 
Likewise, a short arbitrage strategy where the actual futures price is overpriced and incorporating transaction costs is profitable when

$$
F_{t}>C_{t}+X-P_{t}+T C
$$

In sum, either (3) or (4) results in an arbitrage opportunity that is profitable after transaction costs are considered. Depending on whether the actual futures price is underpriced or overpriced in relation to the theoretical price, a long or short arbitrage strategy should be executed.

It should be noted that there are no restrictions preventing an arbitrager in taking short positions in the futures and writing option contracts. Thus, in contrast with other studies that utilise equities, the put-call-futures parity relationship on the SFE considered in this study should hold more strongly than in other types of markets.

\subsection{Some technical issues}

There are many issues relating to prices which can cause problems for studies that seek to test the PCFP. The issues such as stale prices, legging risk and nonsynchronous prices are some major concerns that must be accounted for.

The non-synchronous price problem is mitigated in this paper by matching the futures and futures option contracts within a one-minute interval. Tick-by-tick data covering the period from $2^{\text {nd }}$ January 2001 to $31^{\text {st }}$ March 2004 that is time-stamped to the nearest second permits the contracts to be matched within a narrow time interval. Although a wider interval would have enabled a much larger sample size, the issue of synchronous prices is regarded as more important than increasing the sample size using a wider interval. The intuition behind this point is rather simple. If a wider interval is chosen, such as a five or ten minute interval, then analysing the ex post results would have introduced significant legging risk and increased the chances of stale prices. This occurs because if the transaction prices are for example ten minutes apart, then the markets might have moved causing a problem with establishing each leg in the futures and option markets. For this reason, it is considered more important to match the three contracts within a narrow time interval than it is to get a larger sample size by increasing the interval and not allowing prices to be synchronous. 
This paper takes into account the realistic transaction costs that an arbitrager has to incur, including the implicit bid-ask spread. Ex post tests are undertaken to provide evidence on the size and frequency of arbitrage profits while ex ante tests help to illuminate on the dynamic efficiency of the markets.

\subsection{Ex ante tests}

To conduct ex-ante tests, the following procedure is employed. Firstly, the ex post profitable matched trios for members are used to find securities which have traded at a later time during the day. For each security that forms a trio, a search is conducted which finds a contract from the original tick-by-tick dataset that has the same contract specifications as the original ex post contract but is lagged up to 3 minutes. This implies that an arbitrage opportunity which is examined ex post (lag $=0$ minute) is entered into at prices up to 3 minutes later (lag $=3$ minutes). This considers the execution delay that an arbitrager needs to enter into the positions.

As Lee and Nayar (1993) state, the number of observations used in the ex ante tests is not necessarily the same as the ex post observations because a time-stamped set of matched trios may not exist for each violation. Note that if all three contracts do not trade within 3 minutes then these trios are not used in the ex ante tests because they are the ex post trios. It is important to understand that it only takes one change in the price of one of the three contracts which make up the trio to disrupt the PCFP relation and cause the deviation to be corrected. Therefore, if any one of the three contracts trades within 3 minutes which have the same contract specifications as the original ex post trios, then these are examined in the ex ante tests. Only one of the three contracts needs to be traded within 3 minutes to warrant an ex ante test. This will provide an analysis of the dynamic efficiency of the futures and options market.

Given an ex post mispricing, the ex ante tests required waiting up to 3 minutes to eliminate an arbitrage opportunity at prices that prevailed in the future. It should be noted that one minute may be enough time to execute an arbitrage opportunity. The lag of up to 3 minutes used in paper provides more than enough time for a trader to execute an arbitrage opportunity. 


\section{Contract specifications and data}

\subsection{Contract specification}

There are two financial exchanges in Australia: the Australian Stock Exchange (ASX) and the Sydney Futures Exchange (SFE). The SFE contracts are examined in this study whereby both futures and options on the futures contracts are traded on one exchange. It should be noted that the ASX has introduced futures contracts which could have been used in this paper for examining arbitrage opportunities. However, these contracts are only fairly new and are not as liquid as the SFE futures contracts. In addition, the ASX has introduced index options which are European in exercise style but the futures options traded on the SFE provide an ideal contract in making inferences in relation to market efficiency because of the marking-to-market feature. The SFE is the tenth largest financial futures and options exchange in the world and is the second largest in the Asia-Pacific region by volume turnover (see www.sfe.com.au ).

The SFE SPI 200 index futures contracts are traded on the SFE written against the S\&P/ASX 200 index which is used as the benchmark equity index for the Australian stock market. SPI 200 Index futures contracts started listing on 02/05/2000. The futures contracts are marked-to-market at the end of each day and valued at \$25 per index point. The minium price movement is one index point (A $\$ 25)$. Trading in these contracts ceases at $12.00 \mathrm{pm}$ on the third Thursday of the settlement month and the contracts have March, June, September and December month cycles out to six quarter months. The contracts are cash settled on the first business day after the expiry date. These contracts can be traded during normal trading hours between 9.50am - 4.30pm and overnight from 5.10pm - 8.00am.

The contract specifications for the options on the SFE SPI 200 index futures are very similar to those of the futures contracts. These futures options are traded on the SFE and written against the S\&P/ASX 200 index. The listing of these contracts also started on $02 / 05 / 2000$. These contracts are termed "pure options" in the literature mainly because they are marked-to-market at the end of each day. This is contrasted with the "conventional" options whereby the premium is paid upfront and in full. The contracts have a \$25 multiplier; however, the minimum price movement that is allowed is 0.5 index points ( $\$$ \$12.50). Expiration months are the same as the futures 
contracts. Both puts and calls are available and the exercise prices are set at intervals of 25 index points with new exercise prices automatically created as the underlying futures price oscillates. The last day of trading in these option contracts is the same as the futures contracts whereby the contracts stop trading on the third Thursday of the settlement month at $12.00 \mathrm{pm}$. These contracts are cash settled and the trading time for these contracts is the same as the futures. Being options on futures contracts, expiring contracts which are in-the-money allow the holder to enter into a futures contract at the exercise price. The options are American in exercise style which implies they can be exercised on any day up to and including the last day of trading. Table 1 below provides a summary for the contract specifications for both futures and futures options.

$<<$ Insert Table 1 about here $>>$

\subsection{Data}

The data utilised in this study are in the period from $2^{\text {nd }}$ January 2001 to $31^{\text {st }}$ March 2004 provided by the Sydney Futures Exchange (SFE). Preceding $2^{\text {nd }}$ May 2000 the futures contracts traded on the SFE were called the SFE All Ordinaries equity index futures and only after $2^{\text {nd }}$ May 2000 were the SFE SPI 200 equity index futures introduced. The first 6-7 months of trading in 2000 is omitted from the sample because it is assumed that unusual behaviour of the market would be witnessed in this period as the contracts were introduced. The SFE futures contracts and the SFE futures options data are both extracted from CD-ROMS provided by the SFE. The data is time-stamped to the nearest second and consists of intraday transaction prices for both contracts. ${ }^{3}$ Time-stamped to the nearest second transaction price data consisting of trading date, trading time, and volume among other contract specifications such as the contract month and contract year are used. Trading in the futures contracts surpasses trading in the futures options with 2,403,447 transactions in the futures contracts and only 38,878 and 30,158 transactions in the call and put futures options respectively.

\footnotetext{
${ }^{3}$ Data consisting of bid-ask quotes was not available from the exchange.
} 


\section{3. $\quad$ Matching trios}

Using tick-by-tick data allows the futures-call-put trios to be matched within a narrow time interval for analysis. Matching of the three contracts within a one-minuteinterval mitigates the non-synchronous price problem that has affected other studies that use closing prices.

Call futures options are firstly matched with put futures options that have traded within a one-minute interval. If there is no match then the call option is not used and hence disregarded. Only those matches that satisfy the criteria that the exercise prices of both options are the same, the contract year and month are the same and the contracts are traded on the same day and within one minute of the call futures option contract are utilised. If a put futures option trades within a one minute interval of the call futures option but does not meet the above criteria then the match is not used.

After an option pair is identified, a futures contract which trades closest to the options pair is matched also within a one minute interval. The futures contract must have the same contract month and year as that of the options. If no futures contacts are traded within a one-minute interval then no trios are formed and the option pair is not utilised. This implies that all three contracts must have traded within a one minute interval of one another. This allows prices for all three contracts to be grouped within a narrow interval which mitigates the non-contemporaneous price problem, reduces legging risk by providing a one-minute window and also alleviates the stale price problem by examining trades that have recently taken place.

A total number of 748 trios are found using the above criteria. Table 2 shows the distribution of the matched trios in the trading time difference (in seconds) between all three contracts in a trio. The average time between all three contracts over the whole sample period is fifteen seconds which illustrates that the trios are synchronised.

$<<$ Insert Table 2 about here $>>$

A breakdown of the 748 matched trios in each year is presented Table 3. From the table it is clear that 2001 has the largest number of matched trios with 298 for the 
year. It should be noted that year 2004 only consists of 3 months of data and shows a total of 53 matched trios.

$<<$ Insert Table 3 about here $>>$

Figure 1 shows that February 2002 has the largest number of trios occurring in a single month, with a record number of 47 (6.28\%) matched trios of the total matched trios. Additionally, March 2004 also has a high number of matched trios with 27 (3.61\%) while May 2003 has the least number of matched trios with 4 (0.53\%).

$<<$ Insert Figure 1 about here $>>$

We shall also consider the distribution of arbitrage profits with respect to maturity and moneyness. The time to maturity for a matched trio is simply the contract maturity for the underlying call and put options in the trio. However, the moneyness for a trio requires some extra explanation.

Three distinct classes of moneyness are employed in this paper. For a matched trio, if the futures price is below the exercise price by greater than or equal to $2 \%$, the trio is defined as out-of-the-money (OTM); if the futures price is above the exercise price by greater than or equal to $2 \%$, the trio is defined as in-the-money (ITM); otherwise, it is classified as at-the-money (ATM).

It is important to note that both options have the same strike price which means one option will be ITM and the other will be OTM if the futures price and the exercise prices differ. According to our definition, for an OTM trio, the call futures option is OTM while the put futures option is ITM. Similarly, for an ITM trio, the call futures option is ITM and the put futures option is OTM.

Many studies use moneyness as a proxy of liquidity. For example, Cheng, Fung and Chan (2000) state that futures traders usually hedge their exposure with option contracts. Usually the options that are closest to the futures price have the greatest liquidity and are usually the cheapest. 
It should be noted that the time period under investigation covers only those matched trios that have been traded between the times of 9.50AM and 4.30PM on weekdays. The time period examined includes the opening and closing times of the exchange during each trading day. Any violations outside these times are not examined in this paper. The reason why these trios are removed from the sample is because the bid-ask spread after hours cannot be estimated and quantified with any certainty. The spread after hours can be quite large as not many contracts are traded. If these are included in the overall sample, but the bid-ask spread that an arbitrager has to incur is much wider than the estimate used in this study, then the overall size of arbitrage profits will be overestimated. It is for this reason that these contracts are disregarded from the sample. Additionally, two trios were removed because they had expiry dates in 2005.

\subsection{Transaction costs}

As mentioned by Philips and Smith (1980), the bid-ask spread is an important cost that many studies neglect and it is important to consider this cost. ${ }^{4}$ For member firms, this spread represents an important cost relative to the exchange fees which are only a fraction of the bid-ask spread cost. There is no study offers a panacea to estimating this spread and inferring the trade direction from transaction prices is difficult and less than perfect. For this study, instead of inferring the trade direction from transaction prices and because transaction prices do not state whether a transaction occurred at the bid or ask, an estimate of the spread is used. This estimate was provided from a futures trader. ${ }^{5}$ From conversations with this trader, it is estimated that the bid-ask spread for the futures contracts is one index point (A\$25) which corresponds to the minimum price movement of the futures contract. ${ }^{6}$ Chance (2001) also provides some evidence that the bid-ask spread is usually the value of the minium price movement for the futures. Therefore, for all futures contracts considered, a one index point spread is used to estimate the spread in the futures market. Estimating the bid-ask spread for the futures options is more difficult because it depends on the maturity of the contracts and the moneyness of the options. The trader states that the bid-ask spread in the futures option markets is between 2 to 4 index points. However, although the spread is quoted at 4 index points on the screen, the market makers run

\footnotetext{
${ }^{4}$ It is important to note that not many studies have examined the size of the bid-ask spread in the futures and futures options markets in Australia. This could be a fruitful area for further research. ${ }^{5}$ This information is sourced from Glenn McClellan at M Asset Management.

${ }^{6}$ Lee and Nayar (1993) also use the minium price movement for estimating the bid-ask spread in the futures markets.
} 
ghost like bid-ask spreads which are usually inside this spread. This explains why studies that use data consisting of bid and ask quotes could overestimate the actual cost. Having said this, a conservative estimate of the spread is 3 index points for ATM options. Options that are OTM or ITM require a greater cost and a spread of 4 index points is used.

These estimates are very conservative so any frequent breaches observed in PCFP would provide strong support for market inefficiency. It should be noted that initially two options are needed for the PCFP relationship, however, only one option needs to be closed out at maturity. Hence, for ATM options, a 3 point spread is used for the option that is opened and closed (ITM) while only half the spread or 1.5 index points is used for the option that is OTM because it is not exercised at maturity and expires worthless. This corresponds to a total bid-ask spread cost of 1 index point for the futures, 3 index points for the option that ends up ITM and 1.5 index points for the option that is OTM. The total cost per arbitrage trade is thus 5.5 index points (A \$137.5) for an ATM trio. Additionally, for OTM and ITM options a wider spread is incurred of 4 index points and is used as the estimate. The total figure per arbitrage trade for OTM and ITM tiros is 1 index points for the futures, 4 index points for the option that ends up ITM and 2 index points for the OTM option. Thus the total bidask spread for OTM and ITM tiros is 7 index points (A $\$ 175)$.

Member firms represent the participants with the lowest cost structure and should be used in tests to provide evidence in relation to market efficiency. Thus we focus below on the arbitrage profitability for members. The exchange fee schedule for both SFE futures and futures option contracts need to be considered next. Member firms get charged an exchange fee of $\$ 0.90$ plus $10 \%$ GST per side for transacting in the futures and futures option contracts, that is, for opening and closing the contracts. Basically that is the only fee that is required to enter into the transactions. To eliminate an arbitrage opportunity, an arbitrager needs to enter into three contracts on futures, call and put. The transaction costs needed to establish a position when a mispricing is observed are three one-way SFE fees of $\$ 0.90$ per trade. At expiration, we need to close out our futures contract and the option that is ITM. Both options have the same exercise price which means one option will be ITM while the other will be OTM. This signifies that another fee is incurred at expiration for closing out the futures option which is ITM. 
Therefore, the total fees that member firms will have to outlay to eliminate an arbitrage opportunity are 5 sides of the SFE exchange fees. This is equal to 0.18 index points (A \$ 4.50). Considering the 10\% GST, the total SFE exchange fees incurred by member's amounts to 0.20 index points (A \$4.95). Adding the bid-ask spread of 5.5 index points for ATM trios and 7 index points for OTM and ITM trios, the total costs for members are 5.70 index points (A $\$ 142.50)$ for ATM tiros and 7.2 index points (A\$180) for OTM and ITM trios.

The margin requirement need to establish positions in the futures and futures option contracts is $\$ 1750$ for both contracts. Individual investors have to pay this margin requirement to enter the contracts but these types of participants are not discussed in this paper. SFE members and non-members can post interest bearing securities which means the interest forgone from posting cash can be ignored in this study.

The total costs that need to be considered inconclusive of the implicit bid-ask spread are all added and used as an estimate of the total transaction costs an arbitrager has to incur. To accommodate other market participants whose cost structure does not correspond with those of the member and non-member firms, a sensitivity analysis will be conducted where costs are increased and deviations in the PCFP relation are observed.

\section{Empirical results}

In this section, we analyse the arbitrage profitability. The analysis will involve ex post tests and ex-ante tests that will provide insights into the efficiency of the two derivative markets in Australia.

As previously discussed, the SFE member firms have the lowest transaction costs and are used as the participants which provide evidence in relation to market efficiency. The total cost for members is 5.70 index points (A $\$ 142.50)$ for ATM trios and 7.2 index points (A $\$ 180)$ for OTM and ITM trios. These costs will be used in the analysis to provide evidence on the efficiency of the two derivative markets in Australia. 
All the tables below focus on trading one of each contract. This can be done due to the common multiplier for both the futures and futures options. In reality an arbitrager would execute many contracts when an arbitrage opportunity is present. Finally, all figures in the tables below are expressed in index points where one index point has a multiplier of $\mathrm{A} \$ 25$.

\subsection{Calendar years}

Table 4 presents the results for the whole sample and also when the sample is partitioned based on calendar years. The number of profitable arbitrage opportunities for members stands at 190 (25.40\%) from the total 748 matched trios. This figure is significantly less than 690 (92.25\%) profitable matched trios when zero transaction costs were assumed. It is important to note that these figures are quite high compared to other studies in the literature. For example, a study by Fung and Mok (2001) using transaction data show that the total number of profitable trios for members amounts to 4.34\% only. Additionally, Lee and Nayar (1993) find that 9.5\% of the total sample is profitable for institutional investors.

$<<$ Insert Table 4 about here $>>$

Over the whole sample period, the mean profit is 6.733 index points. Acknowledging that outliers can cause concern when interpreting these results, the median value is also high with 4.3 index points for members. It appears that the size of arbitrage profits is large and highly profitable.

The mean values over the sample for members are high and vary significantly from year to year. Mittnik and Rieken (2000) state that the mean values should be falling over the sample period because market participants would learn how to price these instruments more efficiently given no market impediments restrict the arbitrager from eliminating the arbitrage profit. This pattern is not observed in our case. Year 2001 has the greatest mean value relative to the other calendar years with 9.025 index points. The mean value is 4.991 index points for 2002 and 5.103 points for 2003. An important observation is that the mean for 2003 was higher and the standard deviation is lower relative to 2002. For the 3 months that make up year 2004, the mean value is 3.717 index points. It should be observed that even the median values for members 
over the different calendar years are high with 6.3, 3.3, 4.8 and 3.05 index points for years 2001, 2002, 2003, and 2004 respectively. These values support the conclusion that profitable arbitrage transactions are present.

Now let us consider the frequency of arbitrage opportunities. We need to examine whether these opportunities are clustered around certain years or spread out across the sample. Table 4 indicates that the number of profitable matched trios continues to fall over the whole sample period. The total number of profitable matched trios is 83,68 , 33 and 6 for 2001, 2002, 2003 and 2004 respectively. The total number of profitable matched trios stands at 190 (25.40\%) over the complete sample period consisting of all 748 matched trios. Table 4 also breaks down the frequency of arbitrage opportunities based on each calendar year. Of the total 298 matched trios observed for 2001, 83 (27.85\%) are profitable. Year 2002 has a similar percentage figure with 68 (26.36\%) breaches of PCFP from the total 258 matched trios. We observe that these percentages continue to decrease over the sample period with 33 (23.74\%) and 6 (11.32\%) for years 2003 and 2004 respectively. Although these figures continue to decrease, it is important to understand that the frequency of arbitrage profits is still large with $11.32 \%$ of the total matched trios in the more recent year 2004 showing profits for members. Additionally, a large part of $t$ the total number of matched trios for SFE members (190) are from r 2001 with 83 (43.68\%) of the total. This figure continues to fall over the sample with 68 (35.79\%), 33 (17.37\%) being witnessed for 2002 and 2003 respectively. $^{7}$

These ex post empirical results reveal that arbitrage opportunities are present with 25.40\% of breaches in PCFP being witnessed for SFE members after considering all transaction costs including the implicit bid-ask spread. Although the number of profitable arbitrage trios after considering transactions costs is falling, the number of profitable trios expressed as a percentage of the total matched trios is still large enough to cast some doubt on the efficiency of the two derivative markets in Australia. In addition, because transaction costs have been considered and the contracts used in this paper offer specifications that come very close to allowing market efficiency per se to be examined, it should be noted that this evidence questions the EMH. The total frequency of arbitrage profits is large even in the more

\footnotetext{
${ }^{7}$ Year 2004 is not compared to these figures as only 3 months of data are included.
} 
recent year 2004, while the mean and median values signify that this is a fruitful arbitrage strategy which is profitable.

\subsection{Long versus Short Arbitrage Strategy}

The long and short arbitrage strategies infer information based on the pricing efficiency of the model. A long arbitrage strategy implies that the futures contract is relatively underpriced; the call futures option is relatively overpriced while the put futures option is relatively underpriced. A short arbitrage strategy is just the opposite of the long arbitrage strategy and is the situation whereby the futures is relatively overpriced, the call futures option is relatively underpriced and the put futures option is relatively overpriced. This sub-section presents the size and frequency of arbitrage profits partitioned based on the long and short arbitrage strategies for SFE members. Table 5 presents the results for the whole sample period partitioned based on arbitrage strategies. Additionally, the sample is also partitioned based on both arbitrage strategies and different calendar years.

Firstly, the empirical results for the whole sample are discussed to provide evidence in relation to whether a long or short arbitrage strategy is more profitable and which is viable more frequently. A total of 190 breaches of PCFP are observed consisting of 102 (53.68\%) long arbitrage opportunities and 88 (46.32\%) short arbitrage opportunities. This finding implies that the futures contracts are more frequently underpriced relative to the PCFP. Intuitively, the call futures options are more frequently overpriced while the put futures options are more frequently underpriced. The profitable long arbitrage strategy is more frequent; however, the short arbitrage strategy is more profitable with a mean of 7.359 index points relative to 6.192 index points for the long arbitrage strategy. The standard deviations for both strategies are high with values of 7.517 and 7.070 index points for the short and long arbitrage strategies respectively. Additionally, the median values of 5.05 and 4.30 index points for the short and long arbitrage strategies respectively are much lower than their respective means but are still highly profitable.

$<<$ Insert Table 5 about here $>>$ 
Having discussed the results for the full sample period, we split the whole sample into four sub-samples based on calendar years. Considering the long arbitrage strategy, 2001 has the highest mean profit for SFE members with a mean of 8.500 index points. This result is also consistent with the short arbitrage strategy whereby 2001 appears to be the most profitable. Excluding year 2004 due to the limited number of matched trios, the mean values continue to fall over consecutive years for the long arbitrage strategy. Turning to the short arbitrage strategy, the same conclusions cannot be reached. Although 2001 has the highest mean value, 2002 gives a mean value of 4.363 index points while year 2003 shows a value of 7.065 index points.

Table 5 also reports the frequency of profitable matched trios when the sample is stratified based on both calendar years and arbitrage strategies. Among the 83 profitable matched trios in 2001, 40 (48.19\%) are profitable with the long arbitrage strategy while 43 (51.81\%) are profitable with the short arbitrage strategy. However, the pattern for year 2002 is quite different, where we see 44 (64.71\%) of the total profitable trios are profitable with the long arbitrage strategy while 24 (35.29\%) are profitable with the short arbitrage strategy. This implies that the futures are more frequently underpriced relative to the PCFP in this year by a large amount. Of the total profitable trios in year 2003, 16 (48.48\%) are profitable with the long arbitrage strategy and 17 (51.52\%) are profitable with the short arbitrage strategy. Finally, in 2004 there are more profitable opportunities with the short arbitrage strategy relative to the long arbitrage strategy implying more frequent overpriced futures.

It is interesting to see that the total number of profitable matched trios in each period relative to the total matched trios for each period is large. For the long arbitrage strategy, there are $44(17.05 \%)$ profitable trios among the total 258 matched trios in 2002, while there are only 40 (13.42\%) trios from 298 matched trios in 2001; Further, there are $16(11.51 \%)$ trios from the total 139 matched trios in 2003 are profitable while only a small number is observed in 2004.

Turning to the short arbitrage strategy, there are 43 (14.43\%) profitable trios from the total 298 matched trios in 2001; 24 (9.30\%) profitable trios from 68 matched trios in 2002, and 17 (12.23\%) profitable trios from a total of 33 matched trios in 2003. These findings imply that a large number of profitable arbitrage opportunities are evident even in the more recent period examined. These trios are large enough in size and 
frequency to question the efficiency and integration of the futures and options markets in Australia.

\subsection{Moneyness}

This subsection presents the empirical results when the sample is partitioned based on moneyness. The whole sample is partitioned based on moneyness and the results are analysed to determine whether the size and frequency of arbitrage opportunities are related to moneyness of the trios.

Table 6 shows that of the 748 matched trios for member firms of SFE, 168 (88.42\%) are ATM, 6 (3.16\%) are OTM while 16 (8.42\%) are ITM trios.

$<<$ Insert Table 6 about here $>>$

Table 6 also reports the total number of profitable matched trios relative to the total number of matched trios for each type of moneyness category. Considering all trios, 168 (30.00\%) breaches of PCFP are observed from the total 560 matched trios that are ATM. The total figures for ITM and OTM matched trios are 118 and 70 trios respectively, of which only 16 (13.56\%) ITM trios and 6 (8.57\%) OTM trios breach PCFP and are profitable. Clearly, the frequency of arbitrage profits is concentrated in ATM trios.

ATM trios report a mean value of 6.712 index points for SFE members. The median value is 4.3 for SFE members which is high. Acknowledging the small number of profitable matched trios, OTM trios have the largest mean value (13.383) and median value (15.55) relative to ATM and ITM trios. ITM trios provide mean values of 4.456 index points. Therefore, the size of arbitrage opportunities is most profitable for OTM trios followed by ATM and then ITM trios. ${ }^{8}$ Having said this, the frequency of arbitrage profits is certainly concentrated in ATM trios showing a large number of violations relative to OTM and ITM trios.

\footnotetext{
${ }^{8}$ One must be cautious in interpreting the results for OTM and ITM trios as the sample sizes are both small.
} 


\subsection{Maturity}

This sub-section addresses the maturity (in days) of the profitable arbitrage opportunities for the SFE members. The goal here is to see whether the arbitrage opportunities concentrate on contracts with certain maturities. The results are presented in Table 7 below.

$<<$ Insert Table 7 about here $>>$

It is interesting to see that the longest maturity was 125 days for the profitable trios. Furthermore, the median value for the whole profitable trio is approximately 43 days. The mode observations are the most interesting because they signify the most frequent maturity. The mode value is 62 days for the whole profitable trios. It should also be noted that the profitable opportunities with the short arbitrage strategy have on average a longer maturity and mode than the profitable ones with the long arbitrage strategy.

\subsection{Sensitivity analysis}

This subsection presents a sensitivity analysis of the size and frequency of arbitrage opportunities when transaction costs vary. Transaction costs of 5, 10, 15, 20, 25 and 30 index points are assumed.

It is interesting first to consider the extreme case where transaction costs are assumed to be zero. In this case, there are 690 profitable arbitrage opportunities from the total 748 matched trios. Of these 690 profitable arbitrage opportunities, 349 are profitable with the long arbitrage strategy and 341with the short arbitrage strategy. Table 8 presents the results of the sensitivity analysis.

For the whole sample, the percentage of profitable arbitrage opportunities decreases with increases in transaction costs. If transaction costs are assumed to be 5 index points, then $28.07 \%$ of the whole sample is profitable. This figure falls to $12.57 \%$ when we assume transaction costs of 10 index points. Considering transaction costs of up to 20 index points, less than $3 \%$ of the sample signifies a profit. The mean values 
are high with systematic increases in these values as transaction costs increase up to 25 index points; however, the number of profitable trades continues to decrease with increases in transaction costs. When considering 30 index points the frequency of arbitrage opportunities is very small with only $1.47 \%$ of the sample signifying a profit.

$<<$ Insert Table 8 about here $>>$

Table 8 also partitions the sample based on the arbitrage strategies. Given a transaction cost of 5 index points, 30.37\% of the total long arbitrage opportunities (349) are profitable with long arbitrage strategy and $30.50 \%$ of the total short arbitrage opportunities (341) are profitable with the short arbitrage strategy. These numbers fall to $13.18 \%$ for the long arbitrage strategy and $14.08 \%$ for the short arbitrage strategy when 10 index points are assumed. Thus the number of profitable arbitrage opportunities is high even at a transaction cost of 10 index points. With a transaction cost of 20 index points, however, the frequency of arbitrage profits significantly decreases for the long and short arbitrage strategies.

This table illustrates that even if transaction costs are assumed to be 10 index points (A \$250) more than 12\% of the sample would still be profitable with a mean profit of 7.476 index points. This clearly shows that the number of violations in PCFP is large and profitable for participants who have a cost structure lower than 10 index points. This finding provides further support of market inefficiency and signifies that two derivative markets are less than perfectly integrated.

\subsection{Ex ante results}

Table 9 shows the ex ante arbitrage profit for members of the SFE. It should be noted that as opposed to the ex post tests where the mispricing signal can be exploited without any risk, the ex ante profit is affected by possible price movements during the execution lag so the profits can be negative. This risk is described as immediacy risk by Kamara and Miller (1995). An average lag of 2.27 minutes is observed for the more liquid futures contracts. A much shorter time lag is witnessed for the less liquid futures options. 
It is interesting to see that within 3 minutes the size of arbitrage profits is similar to the ex post results. The ex post data reported a value of 6.733 index points while the ex ante tests show a value of 6.353 index points over the whole sample. The long and short arbitrage strategies also report a lower ex ante profit relative to the ex post profit. Draper and Fung (2002) showed that the average ex post profit is very close to the average ex ante profit for lags less than 3 minutes which is similar to what this paper has witnessed. In addition, only 20 observations from the total 173 matched trios reported a profit of zero or less. This implies that 153 (88.44\%) of the total ex post trios revealed an ex ante profit. It is interesting to note that for 2001, the ex ante profit is 5.963 index points significantly less than 9.025 index points which is observed ex post. The profits for the other years increase with the ex ante tests relative to the ex post results. This casts some doubt on the efficiency of the futures and options market in Australia. It is observed that if an arbitrage opportunity that is examined ex post, it would still be profitable for the arbitrager to execute the transaction within 3 minutes. Similar conclusions are reached by Klemkosky and Resnick (1980) who note that the ex ante results revealed that the majority of the ex post profitable arbitrage trades are also profitable in the ex ante tests whereby five and fifteen minute lags are used.

\section{Conclusion}

In this paper, we have examined the size and frequency of arbitrage profits utilising the futures and futures option contracts traded on the SFE. The results revealed that arbitrage opportunities are present for SFE members whose cost structure is much lower relative to other market participants.

To allow for synchronous prices, the trios are matched within a one-minute interval. This issue is important as non-synchronous prices are a major problem for studies that test PCFP. It is considered more important to match the three contracts within a narrow time interval than to get a larger sample size by increasing the interval and not allowing prices to be synchronous. Transaction costs are considered including the implicit bid-ask spread which is a large cost facing arbitragers. Furthermore, this 
paper provides evidence on the factors that contribute to mispricings and also commented on the ex ante size and frequency of arbitrage profits.

It has been observed that 190 (25.40\%) of the total 748 matched trios are profitable over the complete sample period for SFE members. The mean profit is in excess of 6.5 index points. These figures are much higher than that observed in the literature. For example, Lee and Nayar (1993) find that only 9.5\% of the sample is profitable after considering transaction costs while Fung and Mok (2001) find even more infrequent violations with $4.34 \%$ and $1.83 \%$ of the sample for members and nonmembers respectively.

It appears that the short arbitrage strategy is more profitable relative to the long arbitrage strategy. However, the long arbitrage strategy occurs more frequently relative to the short arbitrage strategy. This indicates the futures and puts are more frequently underpriced while the calls are more frequently overpriced relative to the PCFP equation. This result is consistent with the findings in Fung and Fung (1997) and Fung and Mok (2001). Cavallo and Mammola (2000) also provide evidence that the short arbitrage strategy is more profitable relative to the long arbitrage strategy.

A large part of the profitable trios are ATM. This result is consistent with Draper and Fung (2002) who note that a large part of the profitable trios cluster around ATM options.

A sensitivity analysis is also conducted to investigate the arbitrage opportunities with various transaction costs. It is found that assuming transactions costs of 10 index points, $12.57 \%$ of the sample is still profitable. The average maturity is about 42 days for the whole sample.

The ex ante results reveal that arbitrage opportunities are still present even within a 3 minute execution period. These results demonstrate that the ex post and ex ante profits are similar for the whole sample.

In conclusion, this paper has presented an accurate and detailed analysis of arbitrage using data from the Australian setting. Although frequent violations of PCFP are observed, the notion that the markets are efficient and integrated may not be 
completely rejected. This is because market frictions might inhibit an arbitrager from eliminating an arbitrage opportunity. However, no such impediments and market frictions can be stated which would inhibit an arbitrager from eliminating an arbitrage opportunity. Transaction costs are considered and arbitrage opportunities are still viable after considering these costs. Therefore, the conclusion reached in this paper is that the size and frequency of arbitrage profits is significant enough to cast doubt on the efficiency and integration between the futures and futures option markets in Australia. Perhaps, an even more accurate conclusion would be to state that the evidence presented in this paper provided strong support for market inefficiency given no impediments restricts an arbitrager from executing an arbitrage opportunity.

A fruitful area for future research is examining the version of PCFP that Tucker (1991) developed using the index futures and option contracts traded on the Australian Stock Exchange (ASX). This version would be employed because the options traded on the ASX do not have the marking-to-marked feature which the SFE futures options have. A premium must be paid to enter into an options contract and this premium must be paid upfront and in full. Additionally, across exchange contracts can be investigated whereby the options traded on the ASX and the futures traded on the SFE can be used to provide evidence on the size and frequency of arbitrage profits. It is assumed that across exchange contracts might result in more frequent violations as an arbitrager would have to trade on two different exchanges to eliminate an observed mispricing.

\section{References}

Asay, M. R. (1982): A note on the design of commodity options contracts, Journal of Futures Markets 2, 1-7.

Cavallo, L. and Mammola, P. (2000): Empirical tests of efficiency of the Italian index options market, Journal of Empirical Finance 7, 173-193.

Chance, D. (2001): An introduction to derivatives and risk management, $5^{\text {th }}$ edition, South Western 
Chen, R, R. and Scott, L. (1993): Pricing interest rate futures options with futures style margining, Journal of Futures Markets 13, 15-22.

Chung, Y. P. (1991): A transactions data test of stock index futures market efficiency and index arbitrage profitability, Journal of Finance 46, 1791-1809.

Cox, J. C. and Rubinstein, M. (1985): Options markets, Prentice-Hall.

Draper, P. and Fung, J. K. W. (2002): A study of arbitrage efficiency between the FTSE-100 index futures and the options contracts, Journal of Futures Markets 22, 358.

Duffie, D. (1989): Futures Markets, Prentice Hill.

Easton, S. A. (1997): Put-call parity with futures-style margining, Journal of Futures Markets 17, 215-227.

Fung, A. K. W. and Fung, J. K. W. (1997): Misprising of index futures contracts: A study of index futures versus index options, The Journal of Derivatives (winter), 3744.

Fung, J. K. W. and Mok, H. M. K. (2001): Index options-futures arbitrage: A comparative study with bid/ask and transaction data, The Financial Review 36, 71-94.

Gould, J. P. and Galai, D. (1974): Transactions costs and the relationship between put and call prices, Journal of Financial Economics 1, 105-129.

Gray, S. F. (1989): Put call parity: An extension of Boundary conditions, Australian Journal of Management 14, 151-169.

Kamara, A. and Miller, T. W. Jr. (1995): Daily and intradaily tests of European putcall parity, Journal of Financial and Quantitative Analysis 30, 519-539.

Klemkosky, R. C. and Resnick, B. G. (1980): An ex ante analysis of put-call parity, Journal of Financial Economics 8, 363-378. 
Lee, J. H. and Nayar, N. (1993): A transaction data analysis of arbitrage between index options and index futures, Journal of Futures Markets 13, 889-902.

Lieu, D. (1990): Options pricing with futures-style margining, Journal of Futures Markets 10, 327-338.

Loudon, G. F. (1988): Put-call parity: evidence from the Big Australian, Australian Journal of Management 13, 53-67.

MacKinlay, A. C. and Ramaswamy, K. (1988): Index-futures arbitrage and the behaviour of stock index futures prices, The Review of Financial Studies 1, 137-158.

Merton, R. C. (1973): The relationship between put and call prices: A comment, Journal of Finance 28, 183-184.

Mittnik, S. and Rieken, S. (2000): Put-call parity and the informational efficiency of the German DAX-index options markets, International Review of Financial Analysis 9, 259-279.

Phillips, S. M. and Smith, C. W. Jr. (1980): Trading costs for listed options, Journal of Financial Economics 8, 179-201.

Stoll, H. R. (1969): The relationship between put and call options prices, Journal of Finance 24, 802-824.

Taylor, S. L. (1990): Put-call parity: evidence from the Australian Options Market, Australian Journal of Management 15, 203-216.

Tucker, A. L. (1991): Financial futures, options and swaps, Minneapolis MN: West Publishing.

Twite, G. (1993): Boundary conditions for SPI futures options with daily futures style margin payments, Working Paper 93-025. 
Table 1 Contract specifications

\begin{tabular}{|c|c|c|}
\hline & SFE Index Futures & SFE Futures Options \\
\hline Name & SFE SPI 200 index futures & SFE Futures Options \\
\hline Underlying Index & S\&P/ASX 200 Index & Same \\
\hline Exchange & Sydney Futures Exchange & Same \\
\hline Multiplier & AUD \$25 per index point & Same \\
\hline Listing Date & $02 / 05 / 2000$ & Same \\
\hline Minimum Price Movement & 1 index point (A $\$ 25)$ & 0.5 of a point (A $\$ 12.50)$ \\
\hline Margin Requirement & $\$ 1750$ & Same \\
\hline Exercise Price & - & Intervals of 25 index points \\
\hline Exercise Style & - & American \\
\hline Settlement & Cash settled & Same \\
\hline Contract Months & $\begin{array}{c}\text { March, June, September, } \\
\text { December out to six quarter } \\
\text { months }\end{array}$ & Same \\
\hline Expiry Day & $\begin{array}{l}\text { The third Thursday of the } \\
\text { settlement month }\end{array}$ & Same \\
\hline Last Trading Day & $\begin{array}{c}\text { The third Thursday at } 12.00 \mathrm{pm} \text { of } \\
\text { each settlement month }\end{array}$ & Same \\
\hline Trading Hours & $\begin{array}{l}\text { 9.50am to } 4.30 \mathrm{pm} \text { and } \\
5.10 \mathrm{pm} \text { to } 7.00 \mathrm{am}\end{array}$ & Same \\
\hline Settlement Day & The first business day after expiry & Same \\
\hline
\end{tabular}

The information presented in this table can be obtained from the SFE website: www.sfe.com.au 
Table 2 Distribution of the matched trios in trading time difference

This table illustrates the number of matched trios for each time difference interval of 5 seconds. Note that the average time difference over the whole sample is 15 seconds.

\begin{tabular}{lc}
\hline Time Difference & Matched Trios \\
\hline$<5$ sec & 337 \\
$6-10 \mathrm{sec}$ & 79 \\
$11-15 \mathrm{sec}$ & 64 \\
$16-20 \mathrm{sec}$ & 46 \\
$21-25 \mathrm{sec}$ & 49 \\
$26-30 \mathrm{sec}$ & 36 \\
$31-35 \mathrm{sec}$ & 31 \\
$36-40 \mathrm{sec}$ & 18 \\
$41-45 \mathrm{sec}$ & 25 \\
$46-50 \mathrm{sec}$ & 26 \\
$51-55 \mathrm{sec}$ & 13 \\
$56-60 \mathrm{sec}$ & 24 \\
\hline Total Matched Trios & 748 \\
\hline
\end{tabular}

Table 3 Distribution of the matched trios in each year

This table illustrates the number of matched trios in each year. Note that 2004 consists of 4 months only.

\begin{tabular}{cc}
\hline Year & Matched Trios \\
\hline 2001 & 298 \\
2002 & 258 \\
2003 & 139 \\
2004 & 53 \\
\hline Total & 748 \\
\hline
\end{tabular}


Figure 1 Distribution of the matched trios in month

This figure illustrates the number of matched trios for each month over the complete sample period.

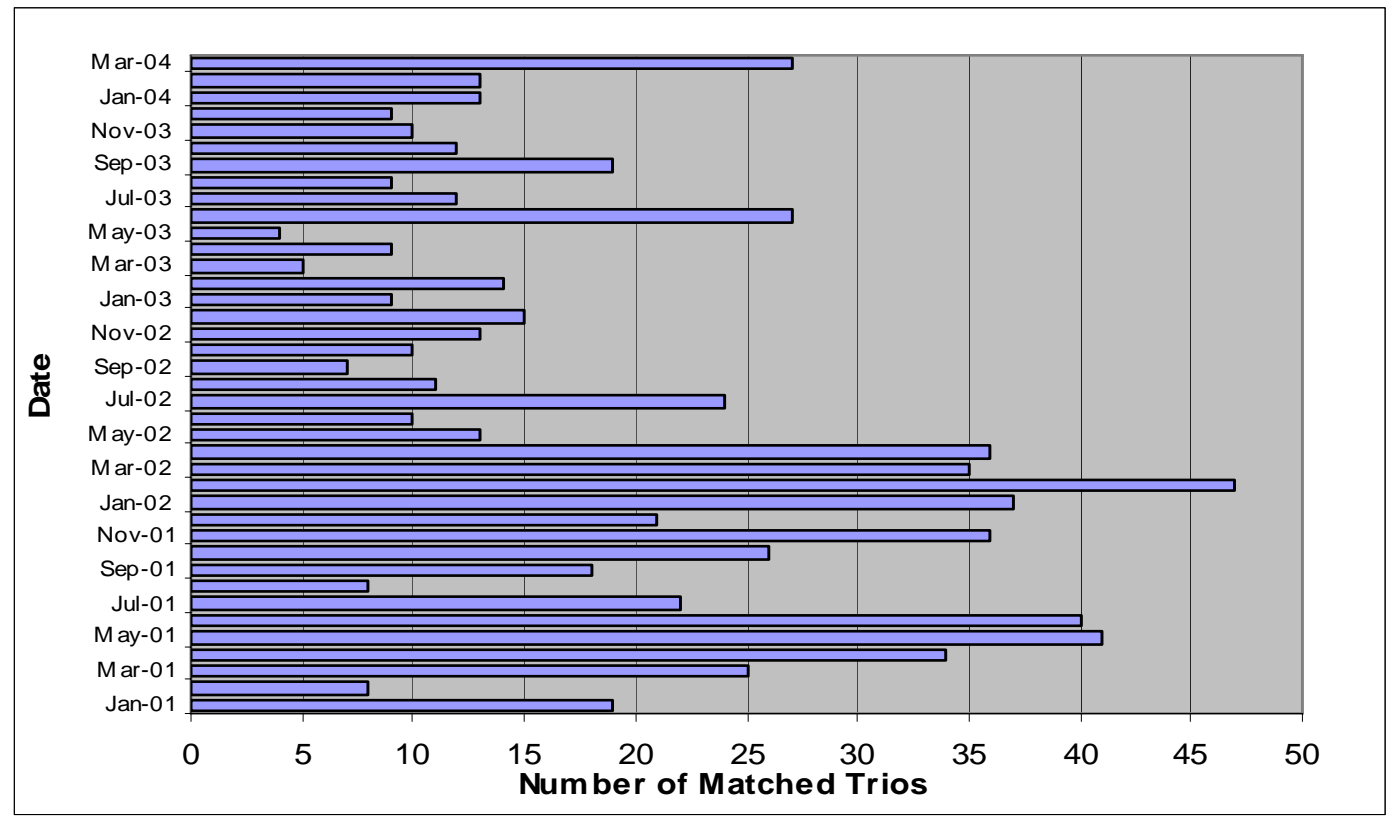


Table 4 Ex post arbitrage profit and calendar year

This table illustrates the ex post arbitrage profit (in points) over the complete sample period ( $2^{\text {nd }}$ January 2001 to $31^{\text {st }}$ March 2004) and in each calendar year for SFE members.

\begin{tabular}{|c|c|c|c|c|c|}
\hline & 2001 & 2002 & 2003 & 2004 & Whole \\
\hline Total Matched Trios & 298 & 258 & 139 & 53 & 748 \\
\hline Mean & 9.025 & 4.991 & 5.103 & 3.717 & 6.733 \\
\hline Median & 6.3 & 3.3 & 4.8 & 3.05 & 4.3 \\
\hline Mode & 2.3 & 3.3 & 0.3 & none & 0.3 \\
\hline Total Arbitrage Profit & 749.1 & 339.4 & 168.4 & 22.3 & 1279.2 \\
\hline Standard Deviation & 9.112 & 5.084 & 4.496 & 3.368 & 7.284 \\
\hline Range & 42 & 23.5 & 17 & 9 & 42 \\
\hline Minimum & 0.3 & 0.3 & 0.3 & 0.3 & 0.3 \\
\hline Maximum & 42.3 & 23.8 & 17.3 & 9.3 & 42.3 \\
\hline Profitable Matched Trios & 83 & 68 & 33 & 6 & 190 \\
\hline Relative Profitable Trios ${ }^{\mathrm{a}}$ & $43.68 \%$ & $35.79 \%$ & $17.37 \%$ & $3.16 \%$ & $100 \%$ \\
\hline Frequency of Total Trios ${ }^{b}$ & $27.85 \%$ & $26.36 \%$ & $23.74 \%$ & $11.32 \%$ & $25.40 \%$ \\
\hline
\end{tabular}

${ }^{\mathrm{a}}$ Total profitable trios for each period divided by the total number of profitable matched trios over the whole sample, e.g. 83/190.

${ }^{\mathrm{b}}$ Total profitable trios for each period divided by the total number of matched trios for that period, e.g. 83/298. 
Table 5 Ex post arbitrage profit and arbitrage strategy

This table illustrates the ex post arbitrage profit (in points) for SFE members over the complete sample period ( $2^{\text {nd }}$ January 2001 to $31^{\text {st }}$ March 2004). The sample is partitioned based on arbitrage strategy and calendar years.

\begin{tabular}{|c|c|c|c|c|c|}
\hline & 2001 & 2002 & 2003 & 2004 & Whole \\
\hline Total Profitable Trios & 83 & 68 & 33 & 6 & 190 \\
\hline \multirow[t]{2}{*}{ Total Matched Trios } & 298 & 258 & 139 & 53 & 748 \\
\hline & \multicolumn{5}{|c|}{ Long Arbitrage Strategy } \\
\hline Mean & 8.500 & 5.334 & 3.019 & 4.300 & 6.192 \\
\hline Median & 6.3 & 3.3 & 1.8 & 4.3 & 4.3 \\
\hline Mode & 2.3 & 3.3 & 0.3 & none & 2.3 \\
\hline Total Arbitrage Profit & 340 & 234.7 & 48.3 & 8.6 & 631.6 \\
\hline Standard Deviation & 8.993 & 5.590 & 2.966 & 2.121 & 7.070 \\
\hline Range & 42 & 23.5 & 8 & 3 & 42 \\
\hline Minimum & 0.3 & 0.3 & 0.3 & 2.8 & 0.3 \\
\hline Maximum & 42.3 & 23.8 & 8.3 & 5.8 & 42.3 \\
\hline Profitable Matched Trios & 40 & 44 & 16 & 2 & 102 \\
\hline Frequency of Profitable Trios ${ }^{\mathrm{a}}$ & $48.19 \%$ & $64.71 \%$ & $48.48 \%$ & $33.33 \%$ & $53.68 \%$ \\
\hline Relative Profitable Trios ${ }^{\mathrm{b}}$ & $39.21 \%$ & $43.14 \%$ & $15.69 \%$ & $1.96 \%$ & $100 \%$ \\
\hline \multirow[t]{2}{*}{ Frequency of Total Trios ${ }^{\mathrm{c}}$} & $13.42 \%$ & $17.05 \%$ & $11.51 \%$ & $3.77 \%$ & $13.64 \%$ \\
\hline & \multicolumn{5}{|c|}{ Short Arbitrage Strategy } \\
\hline Mean & 9.514 & 4.363 & 7.065 & 3.425 & 7.359 \\
\hline Median & 7.3 & 3.3 & 4.8 & 2.05 & 5.05 \\
\hline Mode & 0.3 & 1.3 & 11.3 & none & 0.3 \\
\hline Total Arbitrage Profit & 409.1 & 104.7 & 120.1 & 13.7 & 647.6 \\
\hline Standard Deviation & 9.300 & 4.031 & 4.874 & 4.131 & 7.517 \\
\hline Range & 38 & 12 & 17 & 9 & 38 \\
\hline Minimum & 0.3 & 0.3 & 0.3 & 0.3 & 0.3 \\
\hline Maximum & 38.3 & 12.3 & 17.3 & 9.3 & 38.3 \\
\hline Profitable Matched Trios & 43 & 24 & 17 & 4 & 88 \\
\hline Frequency of Profitable Trios ${ }^{\mathrm{a}}$ & $51.81 \%$ & $35.29 \%$ & $51.52 \%$ & $66.67 \%$ & $46.32 \%$ \\
\hline Relative Profitable Trios ${ }^{\mathrm{b}}$ & $48.86 \%$ & $27.27 \%$ & $19.32 \%$ & $4.55 \%$ & $100 \%$ \\
\hline Frequency of Total Trios ${ }^{c}$ & $14.43 \%$ & $9.30 \%$ & $12.23 \%$ & $7.78 \%$ & $11.76 \%$ \\
\hline
\end{tabular}

${ }^{\mathrm{a}}$ Total profitable trios for each period divided by the total number of profitable matched trios for the period, e.g. 40/83, 44/68.

${ }^{\mathrm{b}}$ Total profitable trios for each period divided by the total number of matched profitable trios of that strategy over all the years, e.g. 40/102, 44/102.

${ }^{\mathrm{c}}$ Total profitable trios for each period divided by the total number of matched trios for the period, e.g., 40/298, 44/258. 
Table 6 Ex post arbitrage profit and moneyness

The table illustrates the ex post arbitrage profit (in points) for SFE members over the complete sample period ( $2^{\text {nd }}$ January 2001 to $31^{\text {st }}$ March 2004) when the sample is partitioned on moneyness. The trios are classified as OTM, ATM and ITM.

\begin{tabular}{lccc}
\hline & OTM & ATM & ITM \\
\hline Total Matched Trios & 70 & 560 & 118 \\
\hline Mean & 13.383 & 6.712 & 4.456 \\
Median & 15.55 & 4.3 & 2.8 \\
Mode & 0.8 & 0.3 & 2.8 \\
Total Arbitrage Profit & 80.3 & 1127.6 & 71.3 \\
Standard Deviation & 10.688 & 7.292 & 3.910 \\
Range & 23 & 42 & 11 \\
Minimum & 0.8 & 0.3 & 0.3 \\
Maximum & 23.8 & 42.3 & 11.3 \\
\hline Profitable Matched Trios $^{\mathrm{a}}$ & 6 & 168 & 16 \\
\hline Relative Profitable Trios & & $8.42 \%$ \\
Frequency of Total Trios $^{\mathrm{b}}$ & $3.16 \%$ & $88.42 \%$ & $13.56 \%$
\end{tabular}

${ }^{\text {a }}$ Total profitable trios for each class divided by the total number of profitable matched trios, e.g. 6/190.

${ }^{\mathrm{b}}$ Total profitable trios for each class divided by the total number of matched trios observed for each class, e.g. 6/70.

Table 7 Maturities of the ex post arbitrage opportunities

This table presents the distribution of maturities of profitable arbitrage opportunities for SFE members. The whole sample is considered as well as partitioning the sample based on long and short arbitrage strategies.

\begin{tabular}{lccc}
\hline & Whole & Long & Short \\
\cline { 2 - 4 } Mean & 42.868 & 40.755 & 45.318 \\
Median & 43.5 & 39 & 50.5 \\
Mode & 62 & 33 & 62 \\
Standard Deviation & 23.247 & 20.801 & 25.698 \\
Range & 123 & 104 & 122 \\
Minimum & 2 & 2 & 3 \\
Maximum & 125 & 106 & 125 \\
Profitable Matched Trios & 190 & 102 & 88 \\
\hline
\end{tabular}


Table 8 Sensitivity analysis with respect to transaction costs

This table illustrates the size and frequency of arbitrage profits when transaction costs vary. Costs of 5, 10, 15, 20, 25 and 30 index points are considered. Results are given for the whole sample and each arbitrage strategy.

\begin{tabular}{|c|c|c|c|c|c|c|}
\hline 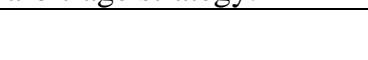 & \multicolumn{6}{|c|}{ Whole Sample } \\
\hline & 5 & 10 & 15 & 20 & 25 & 30 \\
\hline Mean & 7.009 & 7.476 & 8.643 & 10.247 & 9.642 & 5.382 \\
\hline Median & 5 & 5 & 4.5 & 11 & 6.6 & 2.2 \\
\hline Mode & 1 & 5 & 16 & 11 & 6 & 1 \\
\hline Total Arbitrage Profit & 1471.8 & 702.7 & 345.7 & 194.7 & 115.7 & 59.2 \\
\hline Standard Deviation & 7.189 & 7.672 & 8.336 & 7.817 & 6.464 & 6.223 \\
\hline Range & 42.5 & 37.5 & 32.5 & 27 & 21.5 & 17 \\
\hline Minimum & 0.5 & 0.5 & 0.5 & 1 & 1.5 & 1 \\
\hline Maximum & 43 & 38 & 33 & 28 & 23 & 18 \\
\hline Profitable Matched Trios & 210 & 94 & 40 & 19 & 12 & 11 \\
\hline \multirow[t]{2}{*}{ Percentage $^{\mathrm{a}}$} & $28.07 \%$ & $12.57 \%$ & $5.35 \%$ & $2.54 \%$ & $1.60 \%$ & $1.47 \%$ \\
\hline & \multicolumn{6}{|c|}{ Long Arbitrage Strategy } \\
\hline Mean & 6.858 & 7.011 & 9.844 & 10.722 & 9.917 & 6.600 \\
\hline Median & 5 & 5 & 6 & 11 & 6 & 1 \\
\hline Mode & 3 & 5 & 16 & 11 & 6 & 1 \\
\hline Total Arbitrage Profit & 727 & 322.5 & 157.5 & 96.5 & 59.5 & 33 \\
\hline Standard Deviation & 7.054 & 8.113 & 9.600 & 9.121 & 8.224 & 7.956 \\
\hline Range & 42 & 37 & 32 & 27 & 21.5 & 17 \\
\hline Minimum & 1 & 1 & 1 & 1 & 1.5 & 1 \\
\hline Maximum & 43 & 38 & 33 & 28 & 23 & 18 \\
\hline Profitable Matched Trios & 106 & 46 & 16 & 9 & 6 & 5 \\
\hline \multirow[t]{2}{*}{ Percentage $^{\mathrm{b}}$} & $30.37 \%$ & $13.18 \%$ & $4.58 \%$ & $2.58 \%$ & $1.72 \%$ & $1.43 \%$ \\
\hline & \multicolumn{6}{|c|}{ Short Arbitrage Strategy } \\
\hline Mean & 7.162 & 7.921 & 7.842 & 9.820 & 9.367 & 4.367 \\
\hline Median & 5 & 5.25 & 4 & 11 & 8.1 & 3.1 \\
\hline Mode & 1 & 3 & 8 & 3 & 9 & 4 \\
\hline Total Arbitrage Profit & 744.8 & 380.2 & 188.2 & 98.2 & 56.2 & 26.2 \\
\hline Standard Deviation & 7.355 & 7.283 & 7.486 & 6.916 & 4.908 & 4.908 \\
\hline Range & 38.5 & 33.5 & 28.5 & 21 & 13 & 13 \\
\hline Minimum & 0.5 & 0.5 & 0.5 & 3 & 6 & 1 \\
\hline Maximum & 39 & 34 & 29 & 24 & 19 & 14 \\
\hline Profitable Matched Trios & 104 & 48 & 24 & 10 & 6 & 6 \\
\hline Percentage $^{c}$ & $30.50 \%$ & $14.08 \%$ & $7.04 \%$ & $2.93 \%$ & $1.76 \%$ & $1.76 \%$ \\
\hline
\end{tabular}

${ }^{\mathrm{a}}$ This figure is calculated by dividing the total profitable trios by the total number of trios (748).

${ }^{\mathrm{b}}$ This figure is calculated by dividing the total profitable trios by the total number of long arbitrage opportunities (349).

${ }^{\mathrm{c}}$ This figure is calculated by dividing the total profitable trios by the total number of short arbitrage opportunities (341). 


\section{Table 9 Ex ante arbitrage profit}

This table reports the ex ante results for SFE members. Execution is delayed up to 3 minutes to allow time for the arbitrager to establish legs in both markets. If no contracts are traded within 3 minutes the trios are disregarded from the ex ante tests. If for example the call and the put futures options are not traded within 3 minutes, but a futures contract is, then we combine the futures and options using the ex post price of the options and ex ante price of the futures. If there are multiple contracts which can be used the search takes the contract which has traded closest to 3 minutes but does not exceed this time lag.

\begin{tabular}{lccccccc}
\hline & \multicolumn{7}{c}{ Ex Ante Arbitrage Profits } \\
\hline Mean & $\mathbf{2 0 0 1}$ & $\mathbf{2 0 0 2}$ & $\mathbf{2 0 0 3}$ & $\mathbf{2 0 0 4}$ & Whole & Long & Short \\
Median & 5.963 & 6.467 & 7.262 & 6.300 & 6.353 & 6.087 & 6.670 \\
Mode & 4.3 & 4.3 & 8.3 & 5.55 & 4.3 & 4.3 & 4.8 \\
Total Arbit Profit & 4.3 & 3.3 & 8.3 & 5.3 & 0.3 & 4.3 & 0.3 \\
Standard Dev. & 8.471 & 407.4 & 188.8 & 37.8 & 1099.1 & 572.2 & 526.9 \\
Range & 7.367 & 4.827 & 1.975 & 7.442 & 7.112 & 7.850 \\
Minimum & 46.5 & 29 & 19 & 5 & 46.5 & 46.5 & 41 \\
Maximum & -3.2 & -2.7 & -1.7 & 5.3 & -3.2 & -3.2 & -2.7 \\
Count & 43.3 & 26.3 & 17.3 & 10.3 & 43.3 & 43.3 & 38.3 \\
\hline
\end{tabular}




\section{LISTING OF DISCUSSION PAPERS - 2003}

Li S, A Single-Period Model and Some Empirical Evidences for Optimal Asset Allocation with Value-at-Risk Constraints, No 143, March 2003

Valadkhani A, An Empirical Analysis of the Black Market Exchange Rate in Iran, No 144, April 2003

Worthington A, Business Expectations and Preferences regarding the Introduction of Daylight Saving in Queensland, No 145, May 2003

Worthington A, Losing Sleep at the Market: An Empirical Note on the Daylight Saving Anomaly in Australia, No 146, May 2003

Robinson $\mathrm{M}$, Tightening the Results/Funding Link in Performance Budgeting Systems, No 147, May 2003

Worthington A, \& Higgs $\mathrm{H}$, Risk, Return and Portfolio Diversification in Major Painting Marketing: The Application of Conventional Financial Analysis to Unconventional Investments, No 148, June 2003

Valadkhani A, Demand for M2 in Developing Countries: An Empirical Panel Investigation, No 149, July 2003

Worthington $A$, \& Higgs $H$, Modelling the Intraday Return Volatility Process in the Australia Equity Market: An Examination of the Role of Information Arrival in S \& PASX Stocks, No 150, July 2003

Lahiri R, Tax Distortions in a Neoclassical Monetary Economy in the Presence of Administration Costs, No 151 September 2003

Layton A, \& Smith D, Duration Dependence in the US Business Cycle, No 152, August 2003

Valadkhani A, \& Layton A, Quantifying the Effect of GST on Inflation in Australia's Capital Cities: An Intervention Analysis, No 153, September 2003

Worthington A, \& Valadkhani A, Measuring the Impact of Natural Disasters on Capital Markets: An Empirical Application Using Intervention Analysis, No 154, September 2003
Robinson M, The Output Concept and Public Sector Services, No 155, September 2003

Worthington A, Brown K, Crawford M, \& Pickernell D, Socio-Economic and Demographic Determinants of Household Gambling in Australia, No 156, September 2003

Worthington A, \& Higgs $\mathrm{H}$, Tests of Random Walks and Market Efficiency in Latin American Stock Markets: An Empirical Note, No 157, September 2003

(Replacing Previous No 158) Worthington A, \& Higgs $\mathrm{H}$, Systematic Features of High-Frequency Volatility in Australian Electricity Markets: Intraday Patterns, Information Arrival and Calendar Effects, No 158, November 2003

Worthington A, \& Higgs $H$, Weak-form Market Efficiency in European Emerging and Developed Stock Markets, No 159, September 2003

West $\mathrm{T}$, \& Worthington A, Macroeconomic Risk Factors in Australian Commercial Real Estate, Listed Property Trust and Property Sector Stock Returns: A Comparative Analysis using GARCH-M, No 160, October 2003

Lee B, Interstate Comparison of Output and Productivity in the Australian Agricultural Sector - 1991 - 1999, No 161, October 2003

McCarthy S, Hedging Versus not Hedging: Strategies for Managing Foreign Exchange Transaction Exposure, No 162, November 2003

Worthington A, Emergency Finance in Australian Households:

An Empirical Analysis of Capacity and Sources, No 163, November 2003

Worthington C, Debt as a Source of Financial Stress in Australian Households, No 164, November 2003

Robinson M, The Australian Budgeting System: On the Cusp of Change, No 165 , November 2003

Lahiri R, Cooperation v/s Non-cooperation in R\&D Competition with Spillovers, No 166, December 2003

Wolff R, Yao Q, \& Tong $\mathrm{H}$, Statistical Tests for Lyapunov Exponents of Deterministic Systems, No 167, December 2003 
Wolff R, Barnett A, A Time Domain Test for Some Types of NonLinearity, No 168 December 2003

\section{LISTING OF DISCUSSION PAPERS - 2004}

Drew M, Veeraraghavan M, Ye M, Do Momentum Strategies Work? Australian Evidence, No 169, January 2004

Drew M, Mallin M, Naughton T, Veeraraghavan M, Equity Premium: Does it Exist? - Evidence from Germany and United Kingdom, No 170, January 2004

Layton A, Valadkhani A, Measures of National Export Price Volatility Based on the Capital Asset Pricing Model, No 171, January 2004

Drew M, Marsden A, Veeraraghavan M, Small Firm Effect, Liquidity and Security Returns: Australian Evidence, No 172, February 2004

Drew M, Stanford J, Portability of Superannuation Balances, No 173, March 2004

Drew M, Naughton T, Veeraraghavan M Pricing of Equities in China: Evidence from the Shanghai Stock Exchange No 174, May 2004

Valadkhani A, Worthington A, Layton A, An Analysis of the Rising Cost of Education in Australia, No 175, April 2004

Li S, Worthington A, The Relationship Between The Adoption of Internet Banking and Electronic Connectivity: - An International Comparison, No 176, May 2004

Drew M, Marsden A, Veeraraghavan M, Does Idiosyncratic Volatility Matter? - New Zealand Evidence, No 177, May 2004

Guégan D, How Can We Dane the Concept of Long Memory? - An Econometric Survey, No 178, April 2004

Clements A, Hurn S, White S, Discretised Non-Linear Filtering for Dynamic Latent Variable Models: with Application to Stochastic Volatility No 179, May 2004
McCarthy S, Ispriani A, An Operating/Economic Exposure Australian Case Study: Foster's Group Limited, No 180, May 2004

Lahiri R, On Skill Heterogeneity and Inflation, No 181, June 2004

Bianchi R, Drew M, Polichronis J, A Test of Momentum Trading Strategies in Foreign Exchange Markets: Evidence from the G7, No 182, June 2004

Jeisman S, Exchange Market Pressure in Australia, No 183, June 2004

Higgs $\mathrm{H}$, Worthington $\mathrm{A}$, Financial Returns and Price Determinants in the Australian Art Market - 1973-2003, No 184, July 2004

Worthington, A, The distribution of Financial Literacy in Australia, No 185, November 2004

Higgs $\mathrm{H}$, Worthington $\mathrm{A}$, Systematic Features of High-Frequency Volatility in Australian Electricity Markets: Intraday Patterns, Information Arrival and Calendar Effects, No 186, December 2004

\section{LISTING OF DISCUSSION PAPERS - 2005}

Behrens P. Economic Development Strategies: Examples from Europe and Australia, No 187, January 2005

Wilson C, Tidsell C. What Role Does Knowledge of Wildlife Play in Providing Support for Species' Conservation? No 188, February 2005

Zhang S. Consumption Behaviour Under Institutional Transitions in China, No 189, March 2005

Collet J \& Fadili J. Simulation of Gegenbauer Processes Using Wavelet Packets. No 190, March 2005

Clements A \& White S. Non-Linear Filtering With State Dependant Transition Probabilities: A Threshold (Size Effect) SV Model. No 191, April 2005

Clements A \& White S. Non-Linear Filtering For Stochastic Volatility Models with Heavy Tails and Leverage. No 192, April 2005 
Lee B. Significance of Employing a Multilateral Index Formula for

Interstate Comparisons: A Case Study of the Australian Farm Sector

No 193, June 2005 


\title{
QUT
}

Queensland University of Technology

\section{DISCUSSION PAPERS IN ECONOMICS, FINANCE} AND INTERNATIONAL COMPETITIVENESS

Evidence on the Arbitrage Efficiency of SPI Index Futures and Options Markets

\author{
Steven Li \\ and \\ Elia Alfay
}

\section{ISSN 1324-5910}

\section{All correspondence to:}

\section{Dr Steven Li}

Editor, Discussion Papers in Economic, Finance and

International Competitiveness

School of Economics and Finance

Queensland University of Technology

GPO Box 2434, BRISBANE QLD 4001, Australia 